\title{
Growing wrist mass
}

\author{
W C G Peh, T W H Shek, W Y Ip
}

\section{Department of Diagnostic Radiology, Singapore General Hospital, Singapore W C G Peh \\ Department of Pathology, University of Hong Kong, Hong Kong \\ T W H Shek}

\section{Department of} Orthopaedic Surgery, University of Hong Kong, Hong Kong W Y Ip

Correspondence to: Dr W C G Peh, Department of Diagnostic Radiology, Singapore General Hospital, Outram Road, Singapore 169608

gdrpcg@sgh.gov.sg

Accepted 8 November 2000

\begin{abstract}
A 46 year old man presented with a growing mass over his wrist. Erosions of the triquetrum and hamate were present radiographically. Magnetic resonance imaging (MRI) showed a solid mass arising from the extensor carpi ulnaris tendon, which was $\mathbf{T}_{1}$ hypointense and isointense, $T_{2}$ hypointense, and bloomed on gradient echo images. The preoperative diagnosis of giant cell tumour of the tendon sheath was confirmed on histopathological examination of the excised specimen. The clinical, pathological, and imaging features, with emphasis on MRI findings, of this condition are reviewed. (Ann Rheum Dis 2001;60:550-553)
\end{abstract}

\section{Clinical history}

A 46 year old man presented with a one year history of a growing mass in his left wrist. He stated that the mass developed soon after minor contusion to the wrist. On examination, the mass was located over the ulnar aspect of the wrist. It measured about $2 \mathrm{~cm}$ in diameter and was mildly tender. It was fixed in the longitudinal plane to the deep structures but was mobile in the transverse plane. The mass was not attached to the overlying skin, which had a

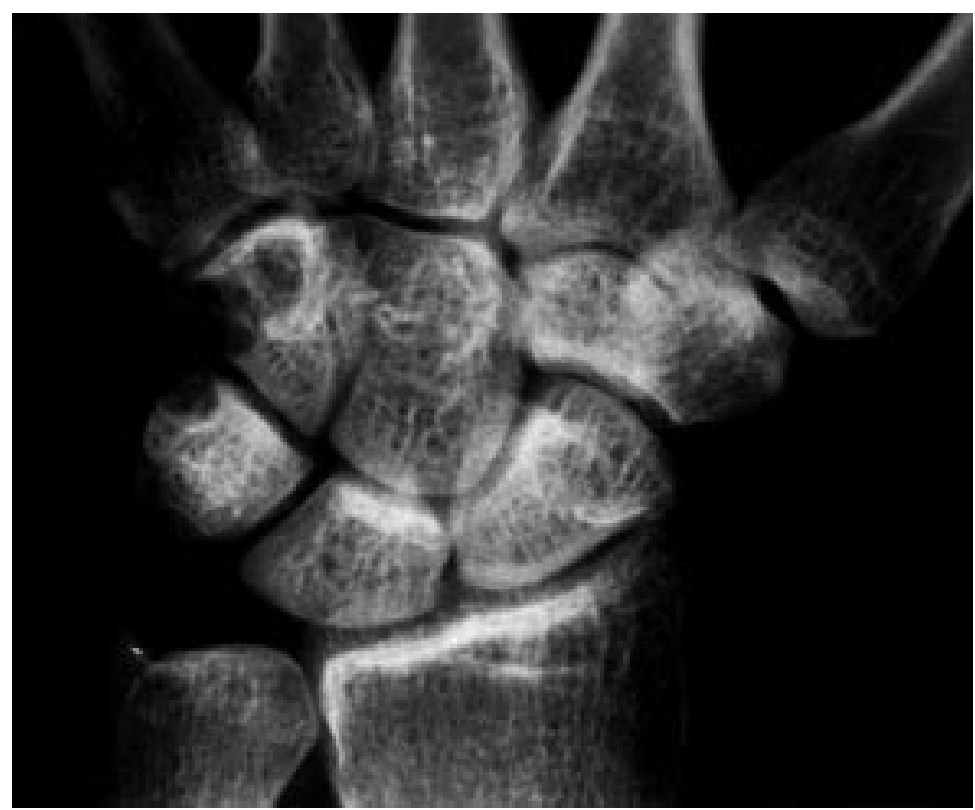

Figure 1 Anteroposterior radiograph of the left wrist showing erosions of the ulnar aspects of the triquetrum and hamate. The margins of the erosions are well defined with a sclerotic rim. normal appearance. Hand and wrist movements were normal, and sensation was intact. There was no other systemic abnormality.

\section{Imaging findings}

A radiograph of the left wrist showed osteolytic involvement of the ulnar aspects of the triquetrum and hamate. Both these bones had well defined "punched-out" erosions with sclerotic margins. The joints were normal and bone density was preserved (fig 1). Magnetic resonance imaging (MRI) demonstrated a well defined, lobulated soft tissue mass eroding the ulnar aspect of the triquetrum and hamate. The base of the fifth metacarpal, pisiform, and ulnar styloid were in close proximity to the mass but were unaffected. The mass arose from the extensor carpi ulnaris tendon, and involved the proximal abductor and flexor digiti minimi muscles. The mass was isointense on $T_{1}$ weighted and proton density weighted images with small areas of hypointensity within, becoming generally more hypointense on $T_{2}$ weighted images. On gradient echo images the lesion appeared more prominent with a further increase in hypointense signal, confirming the magnetic susceptibility effect due to the presence of haemosiderin deposits. There was moderate heterogeneous contrast enhancement, sparing the areas of haemosiderin deposition (figs 2 and 3 ).

\section{Differential diagnosis}

On radiographs, the finding of well defined sclerotic-marginated bony erosions is consistent with a longstanding non-aggressive process. When the joint space is preserved and two adjacent carpal bones are affected, the main differential diagnosis will include intraarticular synovial disease, extra-articular synovial disease arising from the tendon sheath, and extra-articular non-synovial disease.

MRI is the imaging method of choice for evaluating the presence and extent of soft tissue masses of the musculoskeletal system. It is particularly useful for assessing masses in the hand and wrist, where benign lesions predominate. ${ }^{12}$ A specific diagnosis may be made, or strongly suspected, from the characteristic MRI features of certain lesions, such as ganglion, haemangioma, arteriovenous malformation, lipoma, and giant cell tumour of the tendon sheath. ${ }^{1-4}$

Lesions with predominant $T_{2}$ shortening will appear largely hypointense on $T_{2}$ weighted images. $\mathrm{T}_{2}$ shortening may be due to low cellularity, high collagen content, fibrotic scar tissue, 

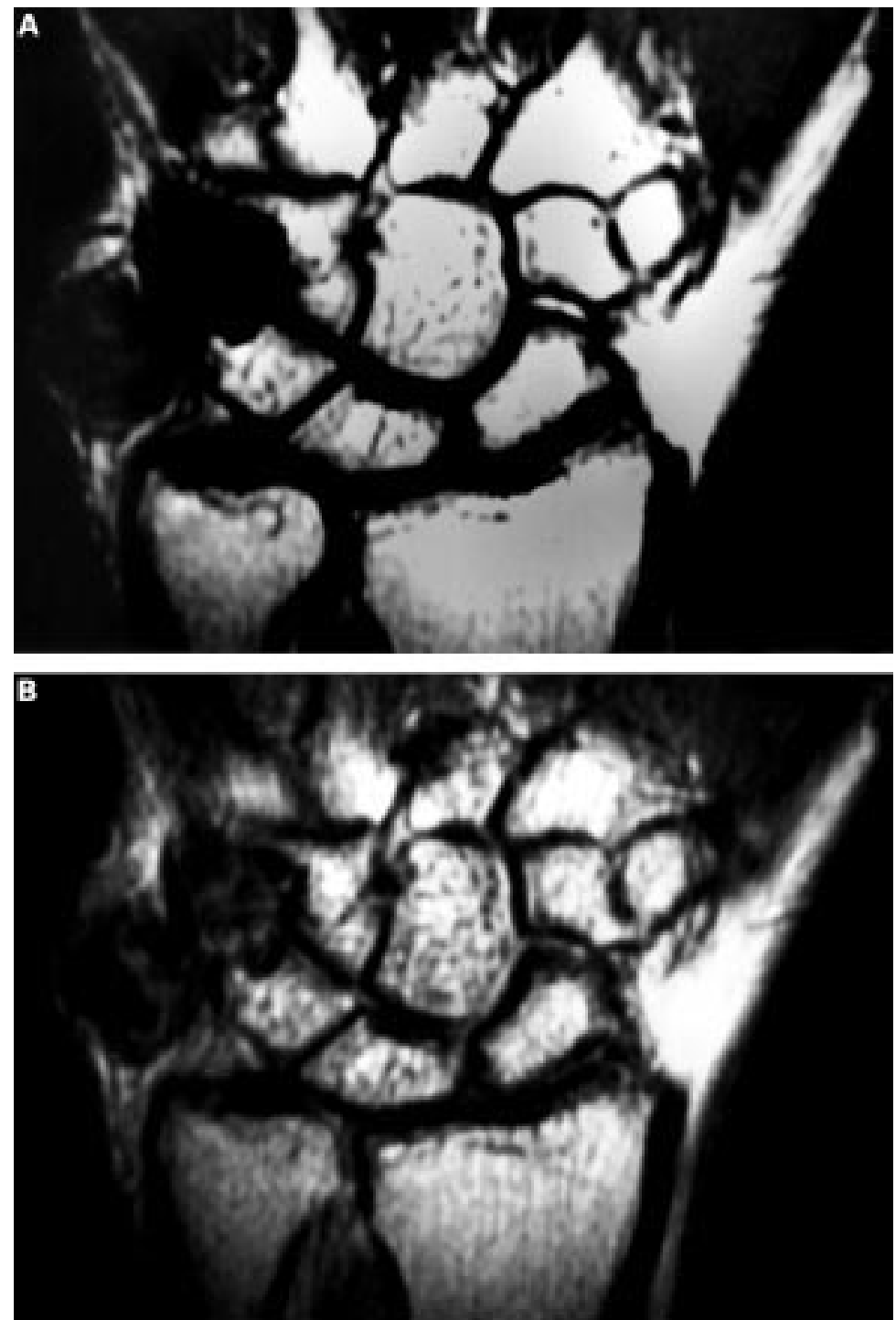

Figure 2 Coronal magnetic resonance images of the left wrist. (A) Spin echo $T_{1}$ weighted and $(B)$ fast spin echo $T_{2}$ weighted images show a lobulated soft tissue mass eroding the triquetrum and hamate. The mass is largely hypointense on both sequences.

mineralised tissue, foreign body, air, amyloid deposition, or the presence of haemosiderin, which produces a magnetic susceptibility effect (box 1)..$^{5}$ Mineralisation due to calcification, ossification, or air can be excluded by careful evaluation of radiographs which should be available when interpreting MR scans of musculoskeletal masses. Fibrotic scar tissue and foreign bodies can usually be identified based on shape and location, together with a careful history and clinical examination. Hypocellular lesions with high collagen content, such as fibromatosis, nodular fasciitis, elastofibroma dorsi, and Morton's neuroma, though all displaying low $\mathrm{T}_{2}$ signal intensity, can be differentiated by morphological appearances, site, and location.

\section{Diagnosis}

The diagnosis was giant cell tumour of the tendon sheath (GCTTS), arising from the extensor carpi ulnaris tendon.

At surgery, a well encapsulated tumour extending from the tendon sheath of the extensor carpi ulnaris tendon and invading adjacent
Box 1 Lesions with low signal intensity on both $T_{1}$ and $T_{2}$ weighted images

Low cellularity/high collagen

- Fibromatosis

- Nodular fasciitis

- Elastofibroma dorsi

- Morton's neuroma

Haemosiderin deposition

-GCTTS/PVNS*

- Haemophilic arthropathy

Synovial amyloid

Fibrotic scar tissue

Mineralised lesions

- Calcification

- Ossification

Foreign body

Air

${ }^{\star}$ GCTTS/PVNS $=$ giant cell tumour of the tendon sheath/pigmented villonodular synovitis.

bones was found. The tumour was fleshy and yellowish-brown in colour. It was attached to the pisiform and thenar muscles. The tumour could be easily separated from the underlying bone and was excised en bloc. The excised specimen measured $2.4 \times 1.7 \mathrm{~cm}$. It had a multilobulated appearance with a yellow-brown cut surface. Histologically, it was a typical GCTTS, which was formed by areas of foam cells as well as areas of mononuclear cells, many of which contained haemosiderin particles (fig 4). The patient made a good postoperative recovery and was well on clinical follow up.

\section{Discussion}

GCTTS is part of the spectrum of a benign synovial proliferative disorder of unknown cause affecting the joints, bursae, and tendon sheaths. GCTTS (or nodular tenosynovitis) represents the extra-articular form of this entity whereas pigmented villonodular synovitis (PVNS) refers to the diffuse and nodular intraarticular form. GCTTS and PVNS are, however, histologically identical, differing in clinical presentation and behaviour, treatment, and prognosis. GCTTS can be further subdivided into the diffuse and localised types. ${ }^{6}$ The diffuse type of GCTTS is typically located in or around large joints and will not be further discussed. This article will concentrate on the localised type of GCTTS that is typically found in the hand and wrist.

Localised GCTTS, although considered a rare entity, is one of the commonest soft tissue masses of the hand. In a review of 3016 soft tissue tumours of the hand and wrist seen at the Department of Soft Tissue Pathology, Armed Forces Institute of Pathology, Washington DC, GCTTS comprised $18 \%$ of benign tumours. As this series consisted largely of consultation cases, there were relatively few ganglia, which is considered to be a much commoner lesion. ${ }^{1}$ In an analysis of 18677 benign soft tissue tumours from the same institution, GCTTS comprised $3.9 \%$ of cases. ${ }^{7}$ Ushijima et al, reporting 207 

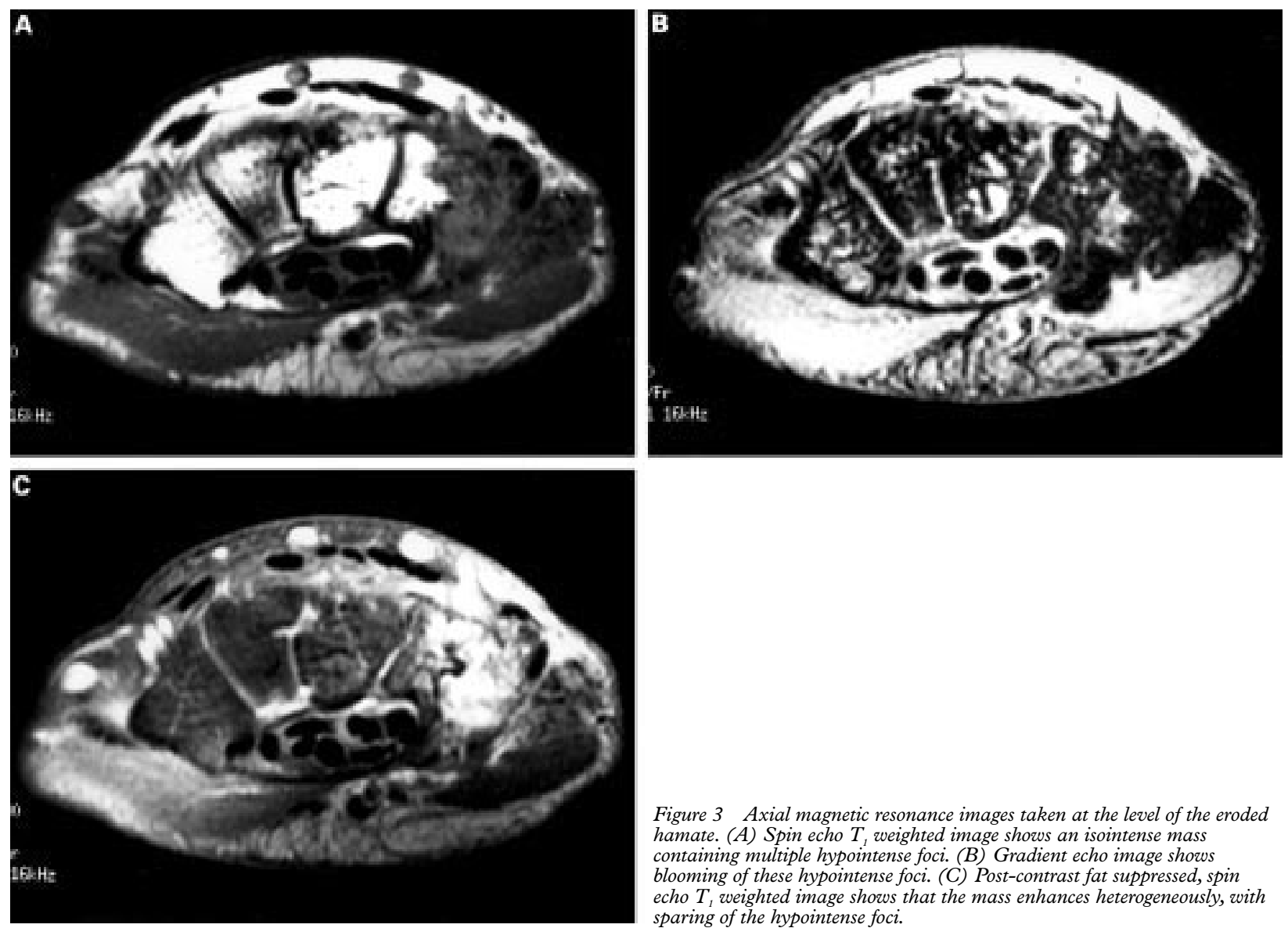

Figure 3 Axial magnetic resonance images taken at the level of the eroded hamate. (A) Spin echo $T_{1}$ weighted image shows an isointense mass containing multiple hypointense foci. (B) Gradient echo image shows blooming of these hypointense foci. (C) Post-contrast fat suppressed, spin echo $T$, weighted image shows that the mass enhances heterogeneously, with sparing of the hypointense foci.

cases of GCTTS, found GCTTS to be more than seven times as common as PVNS.

GCTTS usually affects adults, with a peak incidence in the third to fifth decades of life. There is a slight female predominance, the female:male ratio being $1.5-2.1: 1$. GCTTS is located in the hand and wrist in $65-89 \%$ of lesions. In the hand the volar aspects of the first three digits are most commonly affected. ${ }^{6-10}$ Patients usually present with a painless soft tissue mass. The mass may be slowly growing or be static for many years. The mass is typically small, with an average size of $1.1 \mathrm{~cm} .{ }^{11}$ On palpation, the mass is freely mobile under the skin but remains attached to deeper structures. ${ }^{8-10}$
At gross pathological examination, GCTTS is typically seen as a small rubbery well encapsulated mass. Its colour may be variable, ranging from yellow to brown, depending on the number of foam cells and amount of haemosiderin deposition within the tumour. The mass is often multilobulated. Microscopically, the tumour consists of histiocytic mononuclear cells, multinucleated giant cells, foam cells, and collagenous fibrous strands. Synovial hyperplasia and hypervascularity are features. Variable amounts of haemosiderin are present. The lesion is surrounded by a collagenous capsule that penetrates the lesion, subdividing it into smaller nodules. ${ }^{68}$ Malignant GCTTS is rare but has been described. ${ }^{12}$
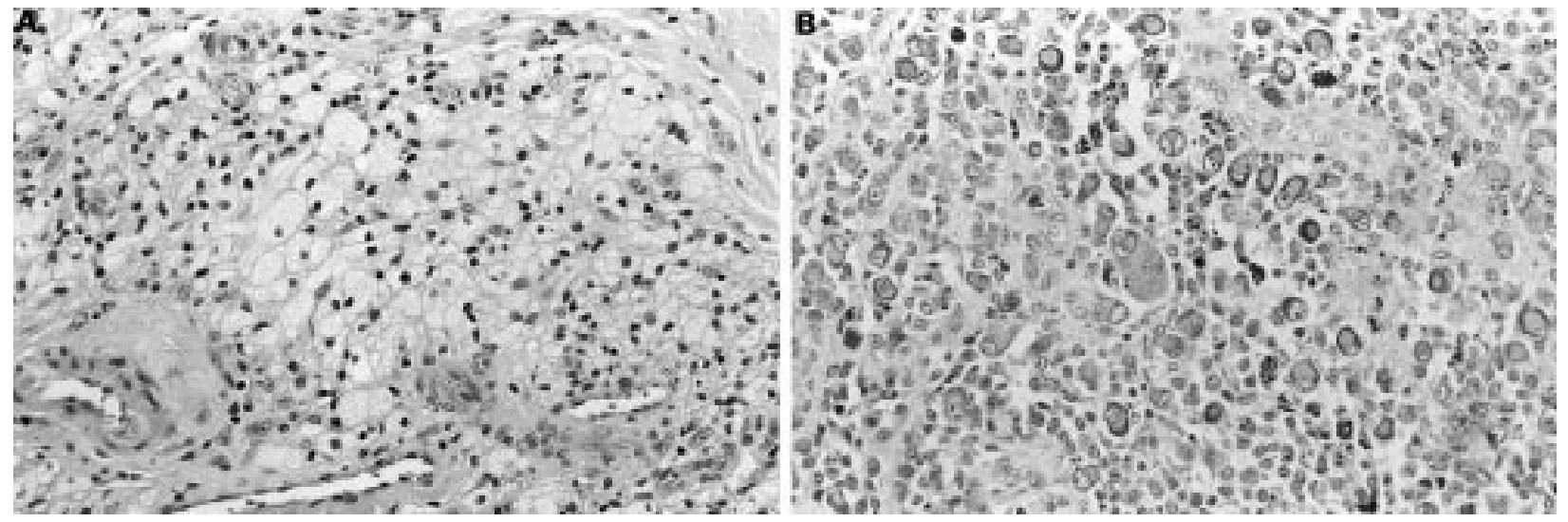

Figure 4 Photomicrographs show a typical giant cell tumour of the tendon sheath characterised by areas of foam cells (A) in a background of mononuclear cells (B), some of which contain haemosiderin particles (haematoxylin and eosin, magnification $\times 330$ ). 
On radiographs, a soft tissue mass may be detectable. Pressure erosions are present in about $15-20 \%$ of cases. ${ }^{810}$ Other associated bone abnormalities include cystic change, degeneration, periosteal reaction, and calcifications. ${ }^{810}$ The presence of calcifications in a periarticular location should suggest the possibility of synovial sarcoma. However, $95 \%$ of synovial sarcomas are extra-articular, though they are often situated near a joint or tendon sheath. Calcifications occur in approximately $30 \%$ of these tumours. ${ }^{13}$

Ultrasonography shows markedly thickened synovium, complex heterogeneous echogenic masses, and loculated joint effusions. On power Doppler ultrasonography, increased flow in the synovial mass is typically seen. A pattern of relatively increased flow in the synovial capsule periphery may be present. These ultrasonographic findings are, however, non-specific and may be seen in synovitis of different aetiologies. ${ }^{1415}$

On computed tomography (CT) the presence of haemosiderin deposits within the lesion may produce areas of high attenuation. As the lesion is hypervascular, contrast enhancement is often present. CT is also useful in detecting small erosions not visible or not clearly defined on radiographs. ${ }^{15-17}$ Generally, imaging techniques, such as ultrasonography, CT, and bone scintigraphy, do not have a significant role in the assessment of GCTTS.

To date, there have only been a limited number of articles analysing the MRI appearances of GCTTS, with the first two reports appearing in $1989 .{ }^{18}{ }^{19}$ This lesion is seen as a well defined soft tissue mass which is located adjacent to or partially enveloping a tendon. It has a predominantly hypointense signal (relative to skeletal muscle) on both $T_{1}$ and $T_{2}$ weighted images. This characteristically low signal intensity is due to abundant collagen as well as haemosiderin deposition, which produces a magnetic susceptibility effect. ${ }^{18-22}$ After contrast injection, strong enhancement is seen because of the presence of numerous proliferative capillaries in the collagenous stroma. ${ }^{23}$

If the typical MRI appearances of GCTTS are present, the diagnosis can easily be made. However, the morphology of individual cases of GCTTS may be variable, and this is reflected in the MRI findings. If less haemosiderin is present, the predominant signal intensity of the lesion tends to be isointense rather than hypointense on $\mathrm{T}_{1}$ weighted images. ${ }^{1921}$ On $\mathrm{T}_{2}$ weighted images, the lesion may be heterogeneously hyperintense, closely resembling other non-specific soft tissue tumours. We have found the presence of a hypointense capsule and multiple hypointense foci to be useful diagnostic features. These hypointense areas are seen on all pulse sequences, being more prominent (blooming effect) with increasing echo time (proton density and $\mathrm{T}_{2}$ weighting) and on gradient echo sequences. This is due to the magnetic susceptibility effect of haemosiderin deposits. We have also noted the presence of scattered tiny $T_{1}$ mildly hyperintense foci, which represents the lipid-laden foam cells found in GCTTS (Peh et al, unpublished data).

GCTTS is treated by local excision. Recurrence is, however, not uncommon, being seen in about $8-20 \%$ of patients. ${ }^{8}{ }^{24}$ In summary, MRI is a valuable diagnostic tool for the preoperative diagnosis of GCTTS, particularly if the characteristic MRI features are present.

We thank Ms Alice Lau for her secretarial assistance.

1 Kransdorf MJ, Murphey MD. MR imaging of musculoskeletal tumors of the hand and wrist. MRI Clinics of North America 1995;3:327-44

2 Peh WCG, Truong NP, Totty WG, Gilula LA. Magnetic resonance imaging of benign soft tissue masses of the hand and wrist. Clin Radiol 1995;50:519-25.

3 Binkovitz LA, Berquist TH, McLeod RA. Masses of the hand and wrist: detection and characterization with MR imaging. Am J Roentgenol 1990;154:323-6.

4 Miller TT, Potter HG, McCormack RR Jr. Benign soft tissue masses of the wrist and hand: MRI appearances. (issue mas

5 Sundaram M, Sharafuddin MJA. MR imaging of benign soft-tissue masses. MRI Clinics of North America 1995;3: 609-27.

6 Kransdorf MJ, Murphey MD. Synovial tumors. In: Kransdorf MJ, Murphey MD. Imaging of soft tissue tumors. Philadelphia: Saunders, 1997:275-316.

7 Kransdorf MJ. Benign soft tissue tumors in a large referral population: distribution of diagnoses by age, sex and location. Am J Roentgenol 1995;164:395-402.

8 Ushijima M, Hashimoto H, Tsuneyoshi M, Enjoji M. Giant cell tumor of the tendon sheath (nodular tenosynovitis). Cancer 1986;57:875-84

9 Oyemade GAA, Abioye AA. A clinicopathologic review of benign giant cell tumors of tendon sheaths in lbadan, Nigeria. Am J Surg 1977;134:392-5.

10 Karasick D, Karasick S. Giant cell tumor of tendon sheath: spectrum of radiologic findings. Skeletal Radiol 1992;21: 219-24.

11 Llauger J, Palmer J, Rosón N, Cremades R, Bagué S. Pigmented villonodular synovitis and giant cell tumors of the tendon sheath: radiologic and pathologic features. Am J Roentgenol 1999;172:1087-91.

12 Carstens PHB, Howell RS. Malignant giant cell tumor of tendon sheath. Virchows Arch A Pathol Anat Histopathol 1979;382:237-43

13 Morton MJ, Berquist TH, McLeod RA, Unni KK, Sim FH. MR imaging of synovial sarcoma. Am J Roentgenol 1991;156:337-40

14 Kaufman RA, Towbin RB, Babcock DS, Crawford AH. Arthroscanography in the diagnosis of pigmented villonodular synovitis. Am J Roentgenol 1982;139:396-8.

15 Lin J, Jacobson JA, Jamadar DA, Ellis JH. Pigmented villonodular synovitis and related lesions: the spectrum of imaging findings. Am J Roentgenol 1999;172:191-7.

16 Jelinek JS, Kransdorf MJ, Utz JA, Berry BH, Thomson JD, Heekin RD, et al. Imaging of pigmented villonodular synovitis with emphasis on MR imaging. Am J Roentgenol 1989;152:337-42.

17 Bravo SM, Winalski CS, Weissman BN. Pigmented villonodular synovitis. Radiol Clin North Am 1998;34: villonod $311-26$.

18 Balsara ZN, Stainken BF, Martinez AJ. MR image of localized giant cell tumor of the tendon sheath involving the knee. J Comput Assist Tomogr 1989;13:159-62.

19 Sherry CS, Harms SE. MR evaluation of giant cell tumors of the tendon sheath. Magn Reson Imaging 1989;7:195201.

20 Demouy EH, Kaneko K, Bear HM, Roriguez RP. Giant cell tumor of the plantar tendon sheath: role of $M R$ imaging in diagnosis - a case report. Clin Imaging 1993;17:153-5.

21 Jelinek JS, Kransdorf MJ, Shmookler BM, Aboulafia AA, Malawer MM. Giant cell tumor of the tendon sheath: MR findings in nine cases. Am J Roentgenol 1994;162:919-22.

22 Khan S, Neumann CH, Steinbach LS, Harrington KD. MRI of giant cell tumor of tendon sheath of the hand: a report of three cases. Eur Radiol 1995;5:467-70.

23 De Beuckeleer L, De Schepper A, De Belder F, Van Goethem J, Marques MC, Broeckx J, et al. Magnetic resoGoethem J, Marques MC, Broeckx J, et al. Magnetic resonance imaging of localized giant cell

24 Moore JR, Weiland AJ, Curtis RM. Localized nodular tenosynovitis: experience with 115 cases. J Hand Surg Am 1984;9:412-17. 